Fetal Diagnosis and Therapy

\title{
Smoking-Induced Changes in the Maternal Immune, Endocrine, and Metabolic Pathways and Their Impact on Fetal Growth: A Topical Review
}

\author{
Sally Sabra ${ }^{\mathrm{a}}$ Eduard Gratacósa, ${ }^{\mathrm{a}}$ Maria Dolores Gómez Roiga, \\ a BCNatal, Barcelona Center for Maternal Fetal and Neonatal Medicine (Hospital Sant Joan de Déu and Hospital \\ Clínic), and bIDIBAPS, University of Barcelona, and Centre for Biomedical Research on Rare Diseases (CIBER-ER), \\ Barcelona, and 'Spanish Maternal and Child Health and Development Network Retics Red SAMID, Health Research \\ Institute Carlos III, Spanish Ministry of Economy and Competitiveness, Madrid, Spain
}

\section{Keywords}

Pregnancy $\cdot$ Smoking $\cdot$ Fetal growth restriction $\cdot$ Immune system · Endocrine system · Metabolic system · Placenta

\begin{abstract}
Perinatal maternal smoking exposure (PMSE) is one of the major environmental risk factors encountered by the fetus. PMSE is usually associated with adverse pregnancy outcomes that may manifest at different stages of life. Nevertheless, fetal growth restriction is the most common smokinginduced side effect. PMSE induces changes in the maternal multiple organ systems. These alterations may affect placentation, which subsequently affects fetal growth. It is worthy to note, however, that the extent of maternal smoking-induced changes depends mainly on the maternal level of susceptibility. Hence, the perinatal pregnancy outcomes vary depending on the interaction between the triad: the maternal, fetal, and placental modifications, making it more complex. In this review, we try to unveil the effect of smokinginduced maternal changes on the maternal immune, endocrine, and metabolic pathways and their impact on fetal growth.

(c) 2017 S. Karger AG, Basel
\end{abstract}

\section{Introduction}

There is no doubt that pregnancy and fetal growth are miracles that are taken for granted. Nevertheless, many factors may meddle with these miracles. During the past 40 years, many studies have shown that perinatal maternal smoking exposure (PMSE) restricts normal fetal growth. Fetal growth restriction (FGR) is a major cause of perinatal morbidity and mortality [1]. FGR is associated with increased risk of stillborn babies, premature birth, hypoxic brain injury, and intrauterine death in a subsequent pregnancy [2].

FGR is defined as fetal weight below 10th percentile adjusted for the gestational age and fetal sex, and affects up to $5-10 \%$ of pregnancies. Therefore, estimated fetal birth weight is a strong predictor of infant survival, and clearly FGR is of huge importance in obstetric practice. FGR can be classified into small for gestation age (SGA) and intrauterine growth restriction (IUGR). SGA fetuses are constitutionally small for normal biological factors as maternal ethnicity, parity, weight, and height [3]. On the other hand, IUGR fetuses are small due to pathological process that prevented them from achieving their growth potential [4]. Other classifications have been developed (e.g., $<5$ th percentile, $<3$ rd percentile) and customized fetal growth potential to replace the population-based cutoff.

Maria Dolores Gómez Roig

Hospital Sant Joan de Déu

Passeig de Sant Joan de Déu, 2

ES-08950 Esplugues de Llobregat, Barcelona (Spain)

E-Mail lgomezroig@sjdhospitalbarcelona.org 
Currently, there is consistent evidence regarding the causality between PMSE and both the FGR and the maternal various organ system changes. Yet, the mechanism is not fully understood.

In this report, we offer a topical review of PMSE and its influence on fetal growth, and other perinatal outcomes in an endeavor to clarify the aforementioned ambiguity. To our knowledge, this is the first review discussing the alterations in the maternal immune, endocrine, and metabolic systems induced by PMSE and their impact on fetal growth.

\section{Smoking Prevalence}

In 2012, the World Health Organization announced that around $20-29 \%$ of women smoke and the majority of this population is in their childbearing period. In the USA and Canada, the prevalence rate is 17.8 and 33\%, respectively. Most importantly, about $70 \%$ of them smoke during pregnancy until delivery [5]. In Spain, about 24.6\% of Spanish women above the age of 16 smoke [6].

Additionally, maternal exposure to noncombustible nicotine-containing cigarettes (i.e., e-cigarettes) and nicotine replacement therapy have to be considered as PMSE; nevertheless, the prevalence rates are still not available [7].

\section{Cigarette Components}

Cigarettes contain many toxic components, including nicotine, carbon monoxide (CO), cadmium (Cd), and polycyclic aromatic hydrocarbons. These toxic components may affect the fetus both directly as well as indirectly. The majority of these components can cross the placental barrier causing fetal injury. In addition, they may also affect placental development and decidualization. Nevertheless, it is uncertain which prenatal adverse effect is associated exactly with which component [8].

Several reports have documented that nicotine crosses the placenta. It has been detected in the fetal circulation and amniotic fluid at levels exceeding maternal serum concentrations by 15 and $54 \%$, respectively, as well as placental tissues $[9,10]$. Moreover, nicotine is known to be orally absorbed. Thus, the fetuses and neonates of smoking mothers are significantly exposed to nicotine during intrauterine and early neonatal life during breastfeeding [11].
Similarly, cotinine, the primary metabolite of nicotine, crosses the placenta [12]. It has been detected at increased levels in the cord blood of neonates of smokers compared to nonsmokers. In addition, cotinine level in serum concentration has been inversely related to the mean neonatal birth weight. Therefore, several studies have considered high cotinine serum concentrations to be predictive of nicotine exposure [13].

\section{Effect of Smoking on the Maternal Multiorgan System}

\section{Immune System}

Normally, pregnancy causes physiological alterations in the maternal immune system to maintain pregnancy and prevent fetal rejection. Maternal immune system adaptations take place locally at the implantation site as well as in the peripheral circulation. Pregnancy is associated with leukocytosis, primarily increased circulation of neutrophils due to the pregnant state-induced stress [14]. Lymphocyte count decreases through the first and second trimesters and increases during the third trimester. During pregnancy, there is a shift from a T helper 1 (Th1) response to a T helper 2 (Th2) that functionally induces maternal tolerance [15]. In addition, the Th1/Th2 cytokine ratio in $\mathrm{T}$ cells of women during pregnancy was significantly decreased. In contrast, the Th1/Th2 ratio was elevated in women with adverse pregnancy outcomes as recurrent spontaneous abortions, indicating a marked shift towards Th1.

In contrast, PMSE may modulate the physiological maternal immune system alterations. PMSE leads to the increased influx of activated leukocytes and lower percentages of regulatory $\mathrm{T}$ cells [16]. Moreover, smoking during pregnancy may affect the balanced function between Th1 and Th2, leading to increased production of inflammatory Th 1 cytokines, chemokines, and growth factors [17].

In the first trimester, the percentages of decidual inflammatory macrophages and NK cells were higher among smokers [18]. Also, Mian et al. [19] have proven that smoking alters NK cell cytotoxic ability leading to increased vulnerability of smoking mothers to infections. DeLoia demonstrated that PMSE causes an increase in the maternal lymphocytes (CD3+) and a decreased percentage of NK cells at 14-20 weeks of gestation in the maternal peripheral blood [20].

Furthermore, smoking leads to the activation and recruitment of inflammatory cells with subsequent release of cytokines IL-8 and IL-6 [21]. Similarly, it is proposed 
that PMSE may result in an altered immune function through the induction of glucocorticoid hypersecretion and increased release of catecholamines, which both inhibit the maternal immune response.

These smoking-induced immune changes have been shown to be associated with unfavorable pregnancy outcomes including recurrent miscarriages, preterm labor, and FGR.

Surprisingly, PMSE has been shown to reduce the risk of preeclampsia (PE) by $32 \%$ in comparison to nonsmokers [22]. Furthermore, the meta-analysis results of 17 studies including approximately 1.8 million subjects where 62,000 patients developed PE revealed significant negative association between PMSE and the incidence of $\mathrm{PE}(\mathrm{RR}=0.67,95 \%$ CI: 0.60-0.75) [23]. Yet, the biologic explanation of such association has not been established. Nevertheless, Llurba et al. [24] showed that PMSE had significantly higher circulating levels of the placental growth factor/soluble fms-like tyrosine kinase-1 ratio compared to nonsmokers, suggesting that PMSE affects placental angiogenesis. Furthermore, Jeyabalan et al. [25] and others are supporting this notion. Hence, it is reasonable to postulate that PMSE may lower the maternal risk of PE, yet has a negative influence on fetal weight.

\section{Hormone Release}

PMSE is associated with changes in the physiological maternal hormonal balance during pregnancy. In a previous study evaluating hormone balance between smoker and nonsmoker pregnant women, serum of smoking mothers showed significantly decreased levels of estradiol, sex hormone-binding globulin, and human chorionic gonadotropin compared to nonsmokers [26]. Placental samples showed lower concentrations of progesterone levels among smoking mothers [27]. Furthermore, maternal serum human placental lactogen, $\beta$-human chorionic gonadotropin, and placental growth hormone levels are negatively correlated with the number of cigarettes smoked per day [28]. Cord plasma concentrations of insulin-like growth factor-1 (IGF-1) and IGF-binding protein-3 were lower in fetuses of smoking mothers [29]. All these hormones interplay to ensure fetal growth; hence, any factor affecting the balanced cross talk may result in FGR through the increased risk of preterm labor and impaired placental function.

Moreover, nicotine, the major component in cigarettes, has a substantial impact on maternal hormones. Nicotine exerts its effects through direct stimulation of acetylcholine receptors, releasing vasoactive catecholamines (i.e., norepinephrine, epinephrine). Also, nico-

The Influence of Smoking on Fetal Growth tine receptor activation leads to the release of acetylcholine, dopamine, serotonin, growth hormone and adrenocorticotrophic hormone, and glutamate (Fig. 1) [30]. All these hormones significantly affect fetal growth [31].

\section{Maternal Metabolism}

Pregnancy induces significant adjustments in the maternal glucose and lipid metabolism mainly due to the placental hormones. In turn, these changes in the maternal metabolism substantially affect fetal growth.

As expected, PMSE also modulates alterations in the maternal metabolism. Smoking is associated with higher serum levels of cholesterol, triglyceride, and lower concentrations of high-densitylipoprotein cholesterol. PMSE also enhances platelet aggregation, reduces the dispensability of blood vessel walls, and induces both prothrombotic and proinflammatory state, leading to placental vascular malfunction. Several reports have confirmed a strong association between smoking and the incidence of diabetes and impairing insulin sensitivity, which may affect the metabolism and growth of the fetus [32]. Hence, any disturbance in this delicate balance between the metabolism and hormones may lead to FGR and placental function impairment.

\section{Effect of Smoking on Fetal Growth}

\section{Fetal Growth}

The gestational age at which FGR is diagnosed has a major impact on the pregnancy outcome. Figueras and Gardosi [33] classified FGR into early- and late-onset FGR. Their results have shown that early-onset FGR is an early embryonic event before 32 weeks of gestation and represents $20-30 \%$ of all FGRs. Late-onset FGR occurs after 32 weeks of gestation and is most frequently associated with abnormal cerebroplacental ratio values [34]. Bar and colleagues [35] suggested that late-onset FGR may represent a different pathophysiologic condition, as differences in placental pathology were noted between early- and late-onset FGR groups. Despite the onset of FGR, early or late, chronic exposure to unfavorable intrauterine environment dictates adverse fetal programming and perinatal outcomes.

\section{Pathophysiology of FGR}

The most common pathophysiological explanation for FGR is impaired fetal oxygen delivery mainly due to decreased oxygen-carrying capacity. This can occur due to maternal diseases causing decreased oxygen-carrying ca-

Fetal Diagn Ther 2017;41:241-250

DOI: $10.1159 / 000457123$ 
Fig. 1. Acetylcholine receptor activation and hormonal release due to PMSE.

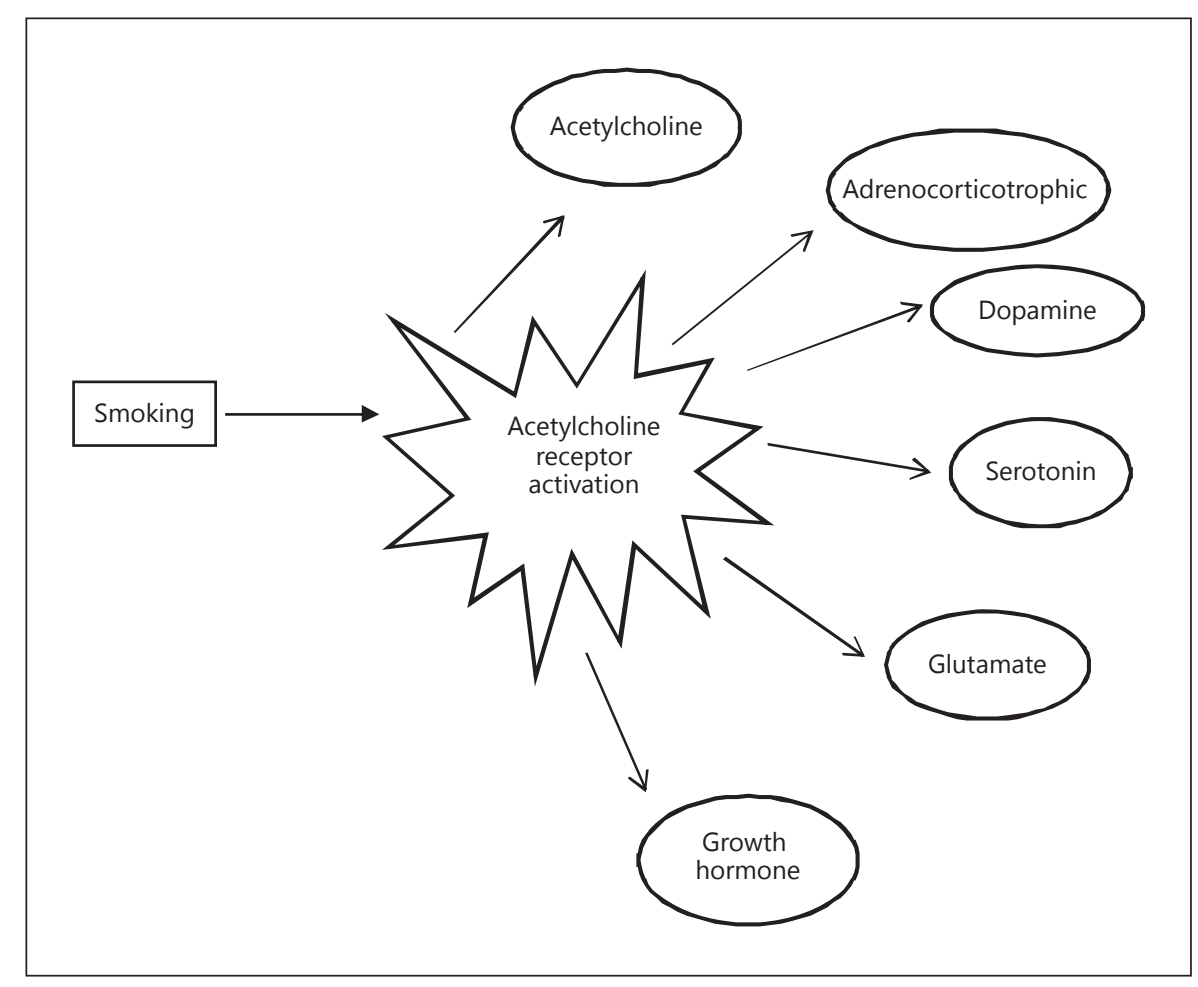

pacity (e.g., chronic hypertension, pregnancy-associated hypertension, heart disease, smoking), dysfunctional oxygen $\left(\mathrm{O}_{2}\right)$ delivery system secondary to maternal vascular disease (e.g., persistent maternal exposure to hypoxic/ toxic environment, vascular disease), or placental damage resulting from maternal smoking, illicit drug use or autoimmune diseases.

Furthermore, both nicotine and cotinine levels in serum concentration have been inversely related to the mean neonatal birth weights. Besides nicotine and cotinine, which are the major nicotine metabolites, $\mathrm{CO}$ has the highest concentration in cigarette smoke, and a higher affinity to hemoglobin than oxygen. Fetal exposure to $\mathrm{CO}$ prevents $\mathrm{O}_{2}$ unbinding; thus, it is converted to carboxyhemoglobin. The latter reduces the tissue oxygenation via competitive inhibition with oxyhemoglobin and left-shift dissociation curve, known as the Haldane effect [36]. Therefore, maternal CO-prolonged exposure can confer significant permanent damage to fetal brain that is sensitive to hypoxia [37]. Cd, another cigarette component has been proven to be both embryotoxic and teratogenic in animal species [38]. In the maternal blood and placentas, elevated $\mathrm{Cd}$ concentrations were inversely related to zinc $(\mathrm{Zn})$ level in cord blood, suggesting that $\mathrm{Cd}$ may hinder $\mathrm{Zn}$ transfer to the fetus that may cause FGR $[39,40]$.

\section{Impact of PMSE}

The exact mechanism behind FGR after PMSE is unclear. However, many studies have documented a strong impact of PMSE on the fetal growth through its effect on placentation, birth weight, and perinatal outcomes.

\section{Placentation}

Placentation is a complex process. As the placenta develops, the villous system undergoes remodeling. Any interruption in the placental vasculature development and remodeling may lead to adverse pregnancy outcomes. Numerous studies have shown that placentas of smoking mothers had a reduction in the number of cytotrophoblasts, increased thickness of the villous membrane as well as accumulation of $\mathrm{Cd}$ with a reduction in fetal capillary volume $[41,42]$. These studies concluded that oxygenation and the passage of nutrients may be limited by these changes. All these placental changes have been inversely related to fetal growth.

As mentioned, maternal nicotine exposure is known to induce vasoconstriction in placental vasculature, decrease placental blood flow, and reduce trophoblast invasion leading to a delay in the establishment of the fetal-maternal circulation [43]. The subsequent reduction 
in oxygen supply may cause placental hypoxia, which is also a trigger for further placental modifications including alternations in both the vasculature and uterine wall invasion in order to maintain blood supply to the fetus [44]. Placenta previa is one of the most common examples of impairment in placental vasculature development. Several studies have shown an association between increased incidence of placenta previa and the dose of tobacco consumed [45]. However, the exact mechanism whereby PMSE induces placenta previa remains speculative.

\section{Birth Weight}

Numerous studies concluded that neonates born to smoking mothers had significantly decreased birth weights compared to nonsmokers [46]. A Brazilian study presented a decrease in the average birth weight of $223.4 \mathrm{~g}$ and a reduction in both birth length and head circumference of 0.94 and $0.69 \mathrm{~cm}$, respectively, of neonates born to smoking mothers [47].

Indeed, it is known that the fetus gains $95 \%$ of its weight in the last 20 weeks of gestation; however, researchers have proven that early pregnancy smoking cessation has the greatest impact on birth weight. The infants of patients who are able to stop smoking early in gestation will have a birth weight comparable to that of infants born to nonsmokers [48].

A significant decrease in fetal size, brain, lung, kidney, and placental volumes was noted in the smoking versus the nonsmoking pregnant group using magnetic resonance imaging to determine the influence of PMSE [49]. The reduction in the fetal organ sizes was noted as early as 22 weeks of gestation; however, no further information was provided about the duration of PMSE and the actual timing of fetal insult.

The maternal smoking dose-dependent effect on fetal weight has been established. For each additional cigarette smoked per day in the third trimester, there was an estimated 27-g reduction in birth weight [50]. Furthermore, changes in the number of daily smoked cigarettes induced changes in the fetal growth curve [51].

Due to the complexity of cigarette composition, it is not clear which of the tobacco components contributes to the reduction in birth weight. However, it is established that cigarette components influence the uterine blood flow and consequently fetal weight.

Doppler studies have been used to demonstrate velocity and wave flow variation between smoking and nonsmoking mothers. A change in the uterine Doppler flow velocity waveform was detected among smoking mothers

The Influence of Smoking on Fetal Growth
[52]. Another study found an acute $76 \%$ increase in the pulsatile index (PI) of the umbilical artery after maternal smoking [53]. However, other studies found no effect on blood flow, velocity, diameter, and the systolic/diastolic ratio, PI, and refractive index in the uteroplacental or fetal blood vessels [54]. This may indicate that the PMSE effects on placental vasculature are not consistent among smoking mothers.

In addition to the PMSE, both the fetus and neonate can have environmental tobacco exposure, known as secondhand smoking. Studies have shown that secondhand smoking exposure is about 22-30\% [55]. Also, PMSE effects, whether active or involuntary exposure, appear to be stronger among older mothers $[56,57]$. In comparison to other risk factors in the prenatal period, smoking is considered one the most harmful with neurobehavioral complications [58].

FGR risk may vary by racial and ethnic groups. Studies noted stronger effects among African-American mothers. These variations may be due to differences in nicotine metabolism among racial groups and/or differences in smoking and exposure patterns [59]. Furthermore, certain populations with genetic polymorphisms may be more vulnerable to damage due to alterations in the metabolic pathways [60].

Neonatal birth weight depends on 2 factors: (1) the gestational age of the fetus at the time of delivery, and (2) the proportion of fetal growth during pregnancy until birth. All the data strongly indicate that PMSE causes preterm labor and reduction in both fetal growth and size. Moreover, the data suggest that fetal programming may vary according to the in utero fetal tobacco exposure timing, maternal/fetal nicotine concentration and maternal susceptibility.

\section{Perinatal Outcomes}

Table 1 shows the relative risk of the adverse pregnancy outcomes associated with PMSE from different studies [61-63].

\section{Reduced Fertility, Spontaneous Abortions, and \\ Preterm Delivery}

Strong association between reduced fertility, spontaneous abortions, preterm labor and female smoking habits has been established by using the level of cotinine to verify tobacco exposure $[64,65]$.

Fetal Diagn Ther 2017;41:241-250

DOI: $10.1159 / 000457123$ 
Table 1. Maternal and perinatal smoking-related adverse outcomes

\begin{tabular}{ll}
\hline Adverse pregnancy outcome & Relative risk \\
\hline Infertility & $1.2-3.6$ \\
Ectopic pregnancy & $1.5-2.5$ \\
Spontaneous abortion & $1.0-1.8$ \\
Placental abruption & $1.4-2.4$ \\
Placenta previa & $1.5-3.0$ \\
Preeclampsia & $0.5-0.7$ \\
PPROM & 2.8 \\
Preterm birth & $1.2-1.6$ \\
Stillbirth & $1.3-1.8$ \\
LBW & 1.75 \\
Neonatal mortality & $1.2-1.4$ \\
Hospitalization of infant or child & $1.5-2.0$ \\
SIDS & 1.33 \\
Oral clefts & $1.2-1.6$ \\
\hline
\end{tabular}

PPROM, preterm premature rupture of membranes; LBW, low birth weight; SIDS, sudden infant death syndrome.

\section{Congenital Anomalies}

The effect of PMSE on the risk of fetal congenital abnormalities has been thoroughly investigated. Pijpers et al. [66] detected a significant increase in fetal heart rate following maternal smoking. The Atlanta and British meta-analysis studies have noticed a significant positive correlation between PMSE and fetal heart defects including conotruncal defects, atrial septal defects, atrioventricular septal defects, and transposition of the great arteries [67, 68]. They have also noticed increased risk for cleft lip with or without cleft palate, clubfoot, craniosynostosis, and gastroschisis [69].

\section{Neurodevelopmental Effect}

An association between maternal smoking and children's lower neurodevelopmental progress including verbal skills, language, reading abilities, and general intelligence skills has been proven. Data from studying the evoked brain responses of infants born to smoking mothers showed atypical patterns of brain organization. Hence, it is suggested that nicotine has a direct effect on the developing fetal brain, causing permanent abnormalities in neurotransmitter regulation [70]. These results indicate that healthy infants who were prenatally exposed to smoking are linked to significant changes in brain physiology that may influence their school performance later on [71]. Furthermore, studies have agreed that offspring of smoking mothers are more vulnerable to mental disorders such as conduct disorder, attention deficit hyperactivity disorder, and cognitive dysfunction [72].

\section{Cardiovascular Effect}

It is well established that cigarettes contain a number of metals, including $\mathrm{Cd}$, lead, and mercury, which catalyze the oxidation of cellular proteins and hence lead to the damage of the vascular wall and the endothelial dysfunction [73]. Also, smoking can enhance platelet-vessel wall interactions through impairing prostacyclin production. Ultimately, this may reduce the elastic properties of the aorta and other arteries, resulting in stiffness of the vessel wall [74]. Apart from these, secondhand exposure to smoking poses a significant cardiovascular health hazard as it impairs endothelium-dependent vasodilation of the coronary arteries and reduces coronary flow reserve [75]. Thus, it is estimated that secondhand smoking increases the risk of developing cardiovascular diseases by $25-30 \%$ [76].

Studies have detected an increase in arterial blood pressure in children who were exposed to maternal smoking $[77,78]$. Studies demonstrated that PMSE was associated with higher blood pressure and a rise in total cholesterol profile in their adult life [79]. Furthermore, persistence of the increased arterial resistance during early life may predispose these fetuses to develop hypertension, left ventricular hypertrophy and cardiovascular disease in adulthood $[80,81]$. These findings may suggest that increased arterial resistance in response to PMSE affects the left atrium and aortic root development in postnatal life [82].

\section{Sudden Infant Death Syndrome}

Sudden infant death syndrome (SIDS) is the unexplained death of a seemingly healthy infant [83]. Its etiology is still unidentified; however, there is a 2 -fold increase in the incidence of SIDS among smoking mothers. Also, SIDS has been associated with secondhand smoke exposure [84].

\section{Assessment of Cigarette Smoking}

Exposure to cigarette smoking can be assessed by 3 means: (1) environmental measurements of the smoke component in the air, (2) self-reporting through questionnaires, and (3) measuring concentrations of smoke components in the body. Environmental measurements obtained by air sampling are suboptimal and do not reflect exposure. Questionnaires are most commonly used for assessing tobacco exposure. However, the reliability of selfreporting has been found to be inaccurate due to awareness of the stigma of smoking during pregnancy [85]. 
Fig. 2. PMSE-induced changes and their

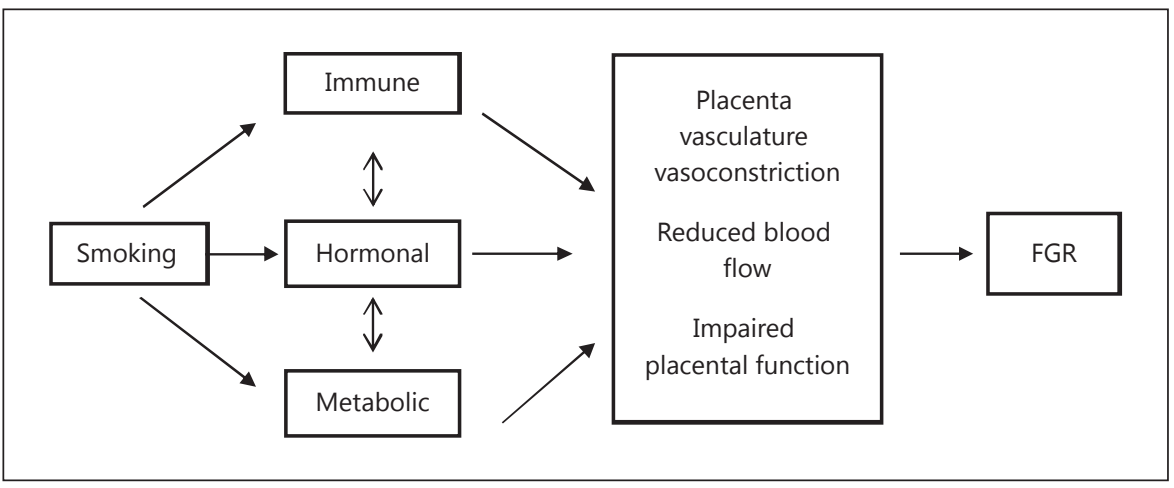
influence on placental function and FGR.

A valid estimation of the risks associated with PMSE depends on accurate measurements of its concentration in the maternal body. Currently, there is no ideal method of measurement. Cotinine is the biomarker of choice; it is detectable in different body fluids, i.e. blood and urine. In addition, cotinine is eliminated over a longer period, resulting in predicting long-term exposure [86]. Cotinine accumulates in the hair during its growth. Therefore, it can be used as a measure of long-term fetal exposure to smoking.

\section{Discussion}

It is well established that PMSE is toxic to both the mother and the fetus. Women who smoke during pregnancy have been observed to have a higher risk of reduced fertility, spontaneous abortion, and preterm labor. In addition, PMSE induces significant changes to the physiological modifications between the immune-hormonalmetabolic maternal systems during pregnancy. These induced alterations may lead to several unfavorable pregnancy outcomes including impaired placental decidualization and function, FGR, as well as various congenital anomalies (Fig. 2). Although a strong negative correlation between PMSE and FGR has been established, many questions remain unanswered.

Nevertheless, various studies have demonstrated that PMSE reduction/stoppage throughout gestation has a significant impact on minimizing the adverse pregnancy outcomes including miscarriage, preterm delivery, perinatal mortality, and FGR $[87,88]$. However, the findings regarding the impact of timing of PMSE cessation/reduction on birth weight have been inconsistent. Some studies have suggested that early pregnancy cessation has the greatest influence on birth weight. Whereas others have

The Influence of Smoking on Fetal Growth shown that only third-trimester maternal cigarette consumption has the strongest association with low birth weight.

Initial studies of PMSE and its impact on fetal growth have shown various degrees of severity of FGR. Nevertheless, these studies failed to show the exact relation between different nicotine and cotinine levels in both maternal and neonatal cord blood, and its negative influence on the neonatal birth weight. It is essential, however, to determine the toxic levels of PMSE, especially due to the different types of cigarettes, their variable contents and nicotine concentrations.

Another area of uncertainty is the critical timing of fetal insult during pregnancy. For example, with the routine third trimester scan, it is possible to detect FGR due to PMSE; nonetheless, the decline in fetal weight may have started at an earlier trimester. Therefore, scheduled early ultrasound screening in an earlier trimester may assist in timely diagnosis of FGR. Moreover, scheduling screening for PMSE itself in line with earlier ultrasound may help early detection of fetal insult during pregnancy.

Recently, Doppler has been utilized to evaluate fetomaternal adaptation to vascular changes induced by PMSE. However, data from Doppler vascular velocity and waveform changes among smoking mothers have been inconsistent. That may reflect variable levels of maternal and fetal adaptation to hypoxia and vascular resistance induced by PMSE. Moreover, the effects of smoking on placental vascular resistance may have been periodic rather than continuous.

Although different women may be exposed to the same amount of tobacco, they may experience different levels of adverse perinatal outcomes including FGR. Therefore, we can postulate that the variable degrees of maternal susceptibility to PMSE result in different pregnancy outcomes, including new FGR classification. Con-

Fetal Diagn Ther 2017;41:241-250 247 
sequently, such discrepancies raise the question regarding the exact mechanism behind the influence of PMSE on fetal birth weight. While the literature provides ample information on the impact of perinatal smoking on FGR, very little has been reported on the exact mechanisms, which may be related to variable genetic and metabolic maternal susceptibility.

To our knowledge, this is the first article reviewing PMSE and its interrelated influence on the maternal immune-endocrine-metabolic system changes as well as fetal growth. At present, our understanding of the adverse effects of PMSE is limited. While the fetomaternal degrees of modification/adaptation to PMSE-induced changes seem conclusive, the effects of timing of fetal insult, dosage of tobacco exposure, and women's genetic susceptibility on pregnancy outcomes are still unknown. Therefore, more research is required to understand the exact mechanisms of PMSE-induced changes on the maternal and fetal outcomes. Furthermore, future studies need to consider the triad of mother, fetus, and placenta as one unit in understanding fetal pathology.

\section{Acknowledgments}

This work has been supported by the Erasmus Programme of the European Union (Framework Agreement No.: 2013-0040). This publication reflects the views of the authors only, and the Commission cannot be held responsible for any use which may be made of the information contained therein.

\section{Disclosure Statement}

The authors report no conflicts of interest. The authors alone are responsible for the content and writing of this article.

\section{References}

1 Unterscheider J, O’Donoghue K, Daly S, Geary MP, Kennelly MM, McAuliffe FM, Hunter A, Morrison JJ, Burke G, Dicker P, Tully EC, Malone FD: Fetal growth restriction and the risk of perinatal mortality-case studies from the multicentre PORTO study. BMC Pregnancy Childbirth 2014;14:63.

2 Jang DG, Jo YS, Lee SJ, Kim N, Lee GS: Perinatal outcomes and maternal clinical characteristics in IUGR with absent or reversed enddiastolic flow velocity in the umbilical artery. Arch Gynecol Obstet 2011:284:73-78.

3 Seaton SE, Yadav KD, Field DJ, Khunti K, Manktelow B: Birthweight centile charts for South Asian infants born in the UK. Neonatology 2011;100:398-403.

4 Cosmi E, Fanelli T, Visentin S, Trevisanuto D, Zanardo V: Consequences in infants that were intrauterine growth restricted. J Pregnancy DOI: 10.1155/2011/36438.

5 Kirkland SA, Dodds LA, Brosky G: The natural history of smoking during pregnancy among women in Nova Scotia. CMAJ 2000; 163:281-282.

6 Sureda X, Martínez-Sánchez JM, Fu M, PérezOrtuño R, Martínez C, Carabasa E, López M J, Saltó E, Pascual JA, Fernández E: Impact of the Spanish smoke-free legislation on adult, non-smoker exposure to secondhand smoke: cross-sectional surveys before (2004) and after (2012) legislation. PLoS One 2014; 9:e89430.

7 Chapman SLC, Wu L: E-cigarette prevalence and correlates of use among adolescents versus adults. J Psychiatr Res 2014:54:43-54.

8 Mund M, Louwen F, Klingelhoefer D, Gerber A: Smoking and pregnancy - a review on the first major environmental risk factor of the unborn. Int J Environ Res Public Health 2013; 10:6485-6499.

9 Berlin I, Heilbronner C, Georgieu S, Meier C, Spreux-Varoquaux O: Newborns' cord blood plasma cotinine concentrations are similar to that of their delivering smoking mothers. Drug Alcohol Depend 2010;107:250-252.

10 Luck W, Nau H, Hansen R, Steldinger R: Extent of nicotine and cotinine transfer to the human fetus, placenta and amniotic fluid of smoking mothers. Dev Pharmacol Ther 1985; 8:384-395.

11 Pastrakuljic A, Schwartz R, Simone C, Derewlany LO, Knie B, Koren G: Transplacental transfer and biotransformation studies of nicotine in the human placental cotyledon perfused in vitro. Life Sci 1998;63:2333-2342.

12 Puig C, Vall O, García-Algar Ó, Papaseit E, Pichini S, Saltó E, Villalb JR: Assessment of prenatal exposure to tobacco smoke by cotinine in cord blood for the evaluation of smoking control policies in Spain. BMC 2012;12:26.

13 Kharrazi M, DeLorenze GN, Kaufman FL, Eskenazi B, Bernert JT, Graham S, Pearl M, Pirkle J: Environmental tobacco smoke and pregnancy outcome. Epidemiology 2004;15: 660-670.

14 Chandra S, Tripathi AK, Mishra S, Amzarul $\mathrm{M}$, Vaish AK: Physiological changes in hematological parameters during pregnancy. Indian J Hematol Blood Transfus 2012;28:144146.

15 Saito S, Nakashima A, Shima T, Ito M: Th1/ Th2/Th17 and regulatory T-cell paradigm in pregnancy. Am J Reprod Immunol 2010;63: 601-610.

16 Prins JR, Hylkema MN, Erwich JJ, Huitema S, Dekkema GJ, Dijkstra FE, Faas MM, Melgert
BN: Smoking during pregnancy influences the maternal immune response in mice and humans. Am J Obstet Gynecol 2012;207:76.

17 Athanassakis I, Vassiliadis S: Interplay between $\mathrm{T}$ helper type 1 and type 2 cytokines and soluble major histocompatibility complex molecules: a paradigm in pregnancy. Immunology 2002;107:281-287.

18 Duriez M, Quillay H, Madec Y, El Costa H, Cannou C, Marlin R, de Truchis C, Rahmati M, Barré-Sinoussi F, Nugeyre MT, Menu E: Human decidual macrophages and NK cells differentially express Toll-like receptors and display distinct cytokine profiles upon TLR stimulation. Front Microbiol 2014;5:316.

19 Mian MF, Lauzon NM, Stämpfli MR, Mossman KL, Ashkar AA: Impairment of human NK cell cytotoxic activity and cytokine release by cigarette smoke. J Leukoc Biol 2008;83: 774-784.

20 Luppi P, Lain K, Jeyabalan A, DeLoia J: The effects of cigarette smoking on circulating maternal leukocytes during pregnancy. Clin Immunol 2007;122:214-219.

21 Thorley AJ, Tetley TD: Pulmonary epithelium, cigarette smoke, and chronic obstructive pulmonary disease. Int J Chron Obstruct Pulmon Dis 2007;2:409-428.

22 Miller EC, Cao H, Wen SW, et al: The risk of adverse pregnancy outcomes is increased in preeclamptic women who smoke compared with nonpreeclamptic women who do not smoke. Am J Obstet Gynecol 2010;203:334

23 Wei J, Liu CX, Gong TT, Wu QJ, Wu L: Cigarette smoking during pregnancy and preeclampsia risk: a systematic review and metaanalysis of prospective studies. Oncotarget 2015;41:43667-43678. 
24 Llurba E, Sánchez O, Domínguez C, Soro G, Goya M, Alijotas-Reig J, Cabero L: Smoking during pregnancy: changes in mid-gestation angiogenic factors in women at risk of developing preeclampsia according to uterine artery Doppler findings. Hypertens Pregnancy 2013;32:50-59.

25 Jeyabalan A, Powers RW, Durica AR, Harger GF, Roberts JM, Ness RB: Cigarette smoke exposure and angiogenic factors in pregnancy and preeclampsia. Am J Hypertens 2008;21: 943-947.

26 Bernstein L, Pike MC, Lobo RA, Depue RH, Ross RK, Henderson BE: Cigarette smoking in pregnancy results in marked decrease in maternal hCG and estradiol levels. Br J Obstet Gynaecol 1989;96:92-96.

27 Piasek M, Blanuša M, Kostial K, Laskey JW: Placental cadmium and progesterone concentrations in cigarette smokers. Reprod Toxicol 2001;15:673-681.

28 Varvarigou AA, Liatsis SG, Vassilakos P, Decavalas G, Beratis NG: Effect of maternal smoking on cord blood estriol, placental lactogen, chorionic gonadotropin, FSH, LH, and cortisol. J Perinat Med 2009;37:364-369.

29 Fang F, Luo ZC, Dejemli A, Delvin E, Zhang $\mathrm{J}$ : Maternal smoking and metabolic health biomarkers in newborns. PLoS One 2015;23: 10.

30 Arneric SP: Neurobiology and clinical pathophysiology of neuronal nicotinic acetylcholine receptors; in Piasecki MP, Newhouse P (eds): Nicotine in Psychiatry: Psychopathology and Emerging Therapies. Washington, American Psychiatric Press, 2000, pp 3-35.

31 Li Y, Gonzalez P, Zhanga L: Fetal stress and programming of hypoxic/ischemic-sensitive phenotype in the neonatal brain: mechanisms and possible interventions. Prog Neurobiol 2012;98:145-165.

32 Behl M, Rao D, Aagaard K, Davidson TL, Levin ED, Slotkin TA, Srinivasan S, Wallinga D, White MF, Walker VR, Thayer KA, Holloway AC: Evaluation of the association between maternal smoking, childhood obesity, and metabolic disorders: a national toxicology program workshop review. Environ Health Perspect 2013;121:170-180.

33 Figueras F, Gardosi J: Intrauterine growth restriction: new concepts in antenatal surveillance, diagnosis, and management. $\mathrm{Am} \mathrm{J} \mathrm{Ob-}$ stet Gynecol 2011;204:288-300.

34 Baschat AA: Neurodevelopment following fetal growth restriction and its relationship with antepartum parameters of placental dysfunction. Ultrasound Obstet Gynecol 2011;37: 501-514.

35 Kovo M, Schreiber L, Ben-Haroush A, Cohen G, Weiner E, Golan A, Bar J: The placental factor in early- and late-onset normotensive fetal growth restriction. Placenta 2013;34: 320-324.

36 Blumenthal I: Carbon monoxide poisoning. J R Soc Med 2001;94:270-272.
37 Sun X, Xu H, Meng X, Qi J, Cui Y, Li Y, Zhang $\mathrm{H}, \mathrm{Xu}$ L: Potential use of hyperoxygenated solution as a treatment strategy for carbon monoxide poisoning. PLoS One 2013;8:e81779.

38 Thompson J, Bannigan J: Cadmium: toxic effects on the reproductive system and the embryo. Reprod Toxicol 2008;25:304-315.

39 Kippler M, Hoque AM, Raqib R, Öhrvik H, Ekström EC, Vahter M: Accumulation of cadmium in human placenta interacts with the transport of micronutrients to the fetus. Toxicol Lett 2010;192:162-168.

40 Kuhnert PM, Kuhnert BR, Erhard P, Brashear WT, Groh-Wargo SL, Webster S: The effect of smoking on placental and fetal zinc status. Am J Obstet Gynecol 1987;157:1241-1246.

41 Burton GJ, Palmer ME, Dalton KJ: Morphometric differences between the placental vasculature of non-smokers, smokers and exsmokers. BJOG 1989;96:907.

42 Genbacev O, McMaster MT, Lazic J: Concordant in situ and in vitro data show that maternal cigarette smoking negatively regulates placental cytotrophoblast passage through the cell cycle. Reprod Toxicol 2000;14:495506.

43 Pastrakuljic A, Derewlany LO, Koren G: Maternal cocaine use and cigarette smoking in pregnancy in relation to amino acid transport and fetal growth. Placenta 1999;20:499-512.

44 Velicky P, Knöfler M, Pollheimer J: Function and control of human invasive trophoblast subtypes: intrinsic vs. maternal control. Cell Adh Migr 2016;10:154-162.

45 Monica G, Lilja C: Placenta previa, maternal smoking and recurrence risk. Acta Obstet Gynecol Scand 1995;74:341-345.

46 Metzger MJ, Halperin AC, Manhart LE, Hawes SE: Association of maternal smoking during pregnancy with infant hospitalization and mortality due to infectious diseases. Pediatr Infect Dis J 2013;32:e1-e7.

47 Zhang L, González-Chica DA, Cesar JA, Mendoza-Sassi RA, Beskow B, Larentis N, Blosfeld T: Maternal smoking during pregnancy and anthropometric measurements of newborns: a population-based study. Cad Saude Publica 2011;27:1768-1776.

48 England LJ, Kendrick JS, Wilson HG, Merritt RK, Gargiullo PM, Zahniser SC: Effects of smoking reduction during pregnancy on the birth weight of term infants. Am J Epidemiol 2001;154:694-701.

49 Anblagan D, Jones NW, Costigan C, Parker AJJ, Allcock K, Aleong R, Coyne LH, Deshpande R, Fenning NR, Bugg G, Roberts N, Pausova Z, Paus T, Gowland PA: Maternal smoking during pregnancy and fetal organ growth: a magnetic resonance imaging study. PLoS One 2013;8:e67223.

50 Bernstein IM, Mongeon JA, Badger GJ, Solomon L, Heil SH, Higgins ST: Maternal smoking and its association with birth weight. Obstet Gynecol 2005;106:986-991.
51 Cnattingius S, Haglund B: Decreasing smoking prevalence during pregnancy in Sweden: the effect on small-for-gestational-age births. Am J Public Health 1997;87:410-413.

52 Teixeira JM, Fisk NM, Glover V: Association between maternal anxiety in pregnancy and increased uterine artery resistance index: cohort based study. BMJ 1999;318:153-157.

53 Coppens M, Vindla S, James DK, Sahota DS: Computerized analysis of acute and chronic changes in fetal heart rate variation and fetal activity in association with maternal smoking. Am J Obstet Gynecol 2001;185:421-426.

54 Müller JS, Antunes M, Behle I, Teixeira L, Zielinsky P: Acute effects of maternal smoking on fetal-placental-maternal system hemodynamics. Arq Bras Cardiol 2002;78:148-155.

55 Alzeidan RA, Mandil AA, Fayed AA, Wahabi HA: The effectiveness of breath carbon monoxide analyzer in screening for environmental tobacco smoke exposure in Saudi pregnant women. Ann Thorac Med 2013;8:214-217.

56 Haug K, Irgens LM, Skjaerven R, Markestad T, Baste V, Schreuder P: Maternal smoking and birthweight: effect modification of period, maternal age and paternal smoking. Acta Obstet Gynecol Scand 2000;79:485-489.

57 Salihu HM, Shumpert MN, Aliyu MH, Kirby RS, Alexander GR: Smoking-associated fetal morbidity among older gravidas: a population study. Acta Obstet Gynecol Scand 2005; 84:329-334

58 Wickström R: Effects of nicotine during pregnancy: human and experimental evidence. Curr Neuropharmacol 2007;5:213-222.

59 Perry BL, Stevens-Watkins D, Oser CB: The moderating effects of skin color and ethnic identity affirmation on suicide risk among low-SES African American women. Race Soc Probl 2013;5:1-14.

60 Hatagima A: Genetic polymorphisms and metabolism of endocrine disruptors in cancer susceptibility. Caud Saude Publica 2002;18: 357-377.

61 Cnattingius S: The epidemiology of smoking during pregnancy: smoking prevalence, maternal characteristics, and pregnancy outcomes. Nicotine Tobacco Res 2004;6(suppl 2):S125-S140.

62 Jaddoe VW, Troe EJ, Hofman A, Mackenbach JP, Moll HA, Steegers EA, et al: Active and passive maternal smoking during pregnancy and the risks of low birthweight and preterm birth: the Generation R Study. Paediatr Perinat Epidemiol 2008;22:162-171.

63 Andres RL, Day MC: Perinatal complications associated with maternal tobacco use. Semin Neonatol 2000;5:231-241.

64 Sieminska A, Jassem E: The many faces of tobacco use among women. Med Sci Monit 2014;20:153-162.

65 George L, Granath F, Johansson AL, Anneren G, Cnattingius S: Environmental tobacco smoke and risk of spontaneous abortion. Epidemiology 2006;17:500-505.
The Influence of Smoking on Fetal Growth
Fetal Diagn Ther 2017;41:241-250

DOI: $10.1159 / 000457123$ 
66 Pijpers L, Wladimiroff JW, McGhie JS, Bom $\mathrm{N}$ : Acute effect of maternal smoking on the maternal and fetal cardiovascular system. Early Hum Dev 1984;10:95-105.

67 Hackshaw A, Rodeck C, Boniface S: Maternal smoking in pregnancy and birth defects: a systematic review based on 173,687 malformed cases and 11.7 million controls. Hum Reprod Update 2011;17:589-604.

68 Kuehl KS, Loffredo CA: Population-based study of transposition of the great arteries: possible associations with environmental factors. Birth Defects Res A Clin Mol Teratol 2003;67:162-167.

69 Carmichael SL, Ma C, Rasmussen SA, Honein MA, Lammer EJ, Shaw GM; National Birth Defects Prevention Study: Craniosynostosis and maternal smoking. Birth Defects Res A Clin Mol Teratol 2008;82:78-85.

70 AlMamun A, Lawlor DA, Alati R, O'Callaghan MJ, Williams GM, Najman JM: Does maternal smoking during pregnancy have a direct effect on future offspring obesity? Evidence from a prospective birth cohort study. Am J Epidemiol 2006;164:317-325.

71 Key APF, Ferguson M, Molfese DL, Peach K, Lehman C, Molfese VJ: Smoking during pregnancy affects speech-processing ability in newborn infants. Environ Health Perspect 2007;115:623-629.

72 Knopik VS: Maternal smoking during pregnancy and child outcomes: real or spurious effect? Dev Neuropsychol 2009;34:1-36.

73 Bernhard D, Csordas A, Henderson B, Rossmann A, Kind M, Wick G: Cigarette smoke metal-catalyzed protein oxidation leads to vascular endothelial cell contraction by depolymerization of microtubules. FASEB J 2005; 19:1096-1107.
74 Kiowski W, Linder L, Stoschitzky K, Pfisterer M, Burckhardt D, Burkart F, Bühler FR: Diminished vascular response to inhibition of endothelium-derived nitric oxide and enhanced vasoconstriction to exogenously administered endothelin-1 in clinically healthy smokers. Circulation 1994;90:27-34.

75 Salahuddin S, Prabhakaran D, Roy A: Pathophysiological mechanisms of tobacco-related CVD. Glob Heart 2012;7:113-120.

76 Alberg AJ, Shopland DR, Cummings KM: The 2014 Surgeon General's report: commemorating the 50th Anniversary of the 1964 Report of the Advisory Committee to the US Surgeon General and updating the evidence on the health consequences of cigarette smoking. Am J Epidemiol 2014;179:403-412.

77 Lawlor DA, Najman JM, Sterne J, Williams GM, Ebrahim S, Smith GD: Associations of parental, birth, and early life characteristics with systolic blood pressure at 5 years of age. Findings from the Mater-University study of pregnancy and its outcomes. Circulation 2004;110:2417-2423.

78 Brion MJ, Leary SD, Smith GD, Ness AR: Similar associations of parental prenatal smoking suggest childhood blood pressure is not influenced by intrauterine effects. Hypertension 2007;49:1422-1428.

79 Power C, Atherton K, Thomas C: Maternal smoking in pregnancy, adult adiposity and other risk factors for cardiovascular disease. Atherosclerosis 2010;211:643-648.

80 Jaddoe VWV, Ridder MAJ, Van Elzen APM, Hofman A, Uiterwaal CSPM, Witteman JCM: Maternal smoking is associated with cholesterol development in the offspring: a 27 years follow-up study. Atherosclerosis 2008;196: $42-48$.
81 Geerts CC, Bots ML, Grobbee DE, Uiterwaal CS: Parental smoking and vascular damage in young adult offspring: is early life exposure critical? The atherosclerosis risk in young adults study. Arterioscler Thromb Vasc Boil 2008;28:2296-2302.

82 Geelhoed JJ, El Marroun H, Verburg BO, van Osch-Gevers L, Hofman A, Huizink AC, Moll HA, Verhulst FC, Helbing WA, Steegers EA, Jaddoe VW: Maternal smoking during pregnancy, fetal arterial resistance adaptations and cardiovascular function in childhood. BJOG 2011;118:755-762.

83 Schoendorf KC, Kiely JL: Relationship of sudden infant death syndrome to maternal smoking during and after pregnancy. Pediatrics 1992;90:905-908.

84 Yolton K, Dietrich K, Auinger P, Lanphear BP, Hornung R: Exposure to environmental tobacco smoke and cognitive abilities among U.S. children and adolescents. Environ Health Perspect 2005;113:98-103.

85 Dietz PM, Homa D, England LJ, Burley K, Tong VT, Dube SR: Estimates of nondisclosure of cigarette smoking among pregnant and nonpregnant women of reproductive age in the United States. Am J Epidemiology 2011;173:355-359.

86 Benowitz NL: Cotinine as a biomarker of environmental tobacco smoke exposure. Epidemiol Rev 1996;18:188-204.

87 Seybold DJ, Broce M, Siegel E, Findley J, Calhoun BC: Smoking in pregnancy in West Virginia: does cessation/reduction improve perinatal outcomes? Matern Child Health J 2012; 16:133-138.

88 Salihu HM, Wilson RE: Epidemiology of prenatal smoking and perinatal outcomes. Early Hum Dev 2007;83:713-720. 